\title{
The Effectiveness of Teaching Methods Used in Graphic Design Pedagogy in Both Analogue and Digital Education Systems
}

\author{
Salman Alhajri \\ Department of Art Education, College of Education, Sultan Qaboos University, Sultanate of Oman
}

Copyright ( $\odot 2016$ by authors, all rights reserved. Authors agree that this article remains permanently open access under the terms of the Creative Commons Attribution License 4.0 International License

\begin{abstract}
Purpose: this paper investigates the effectiveness of teaching methods used in graphic design pedagogy in both analogue and digital education systems. Methodology and approach: the paper is based on theoretical study using a qualitative, case study approach. Comparison between the digital teaching methods and traditional teaching methods was described. Results: the paper illustrated the promises of developing creativity and innovation potentials within graphic design students, highlighted the responsibility of design educators and graphic design students in this improvement. It evaluates the importance of principles found in traditional teaching methods. This paper suggests a set of recommendations and strategies that can enhance various intellectual and physical skills. Conclusions: the study suggests a set of recommendations to develop a framework that would be ideal in developing a new curriculum of graphic design teach for undergraduate students.
\end{abstract}

Keywords Teaching Graphic Design, Graphic Design Curricula, Analogue Education, Computerized Education, Developing Creativity

\section{Introduction}

\section{The Research Problem}

The research problem can be outlined as: the Omani graphic design education system lacks a unified framework towards the concept of creativity. One of the consequences of such a lack is a shortage of pedagogical structured programmes that can enhance creativity of Omani graphics students. It is believed that this is a result of underestimating the importance of creativity in Arabic traditional educational systems in general [1], a system of which the Omani educational context is part. The location of this educational problem within the Omani (Arabic) context will also colour the take on creativity. This is a result, also, of the absence of unified conceptions of creativity in general, Barnard [2] argues that, "We are still operating with an unexamined notion of creativity and we are likely to be stuck with the uncritical and mystifying conception of creativity".

To solve this research problem, at least partly, it is hypothesized that there is an immediate need for a pedagogical model that can offer a systematic approach for graphic design lecturers in Oman to guide them on how to stimulate their students' creativity. It is argued that such a model would be one step towards improving the state of creativity within the Omani design education system. 


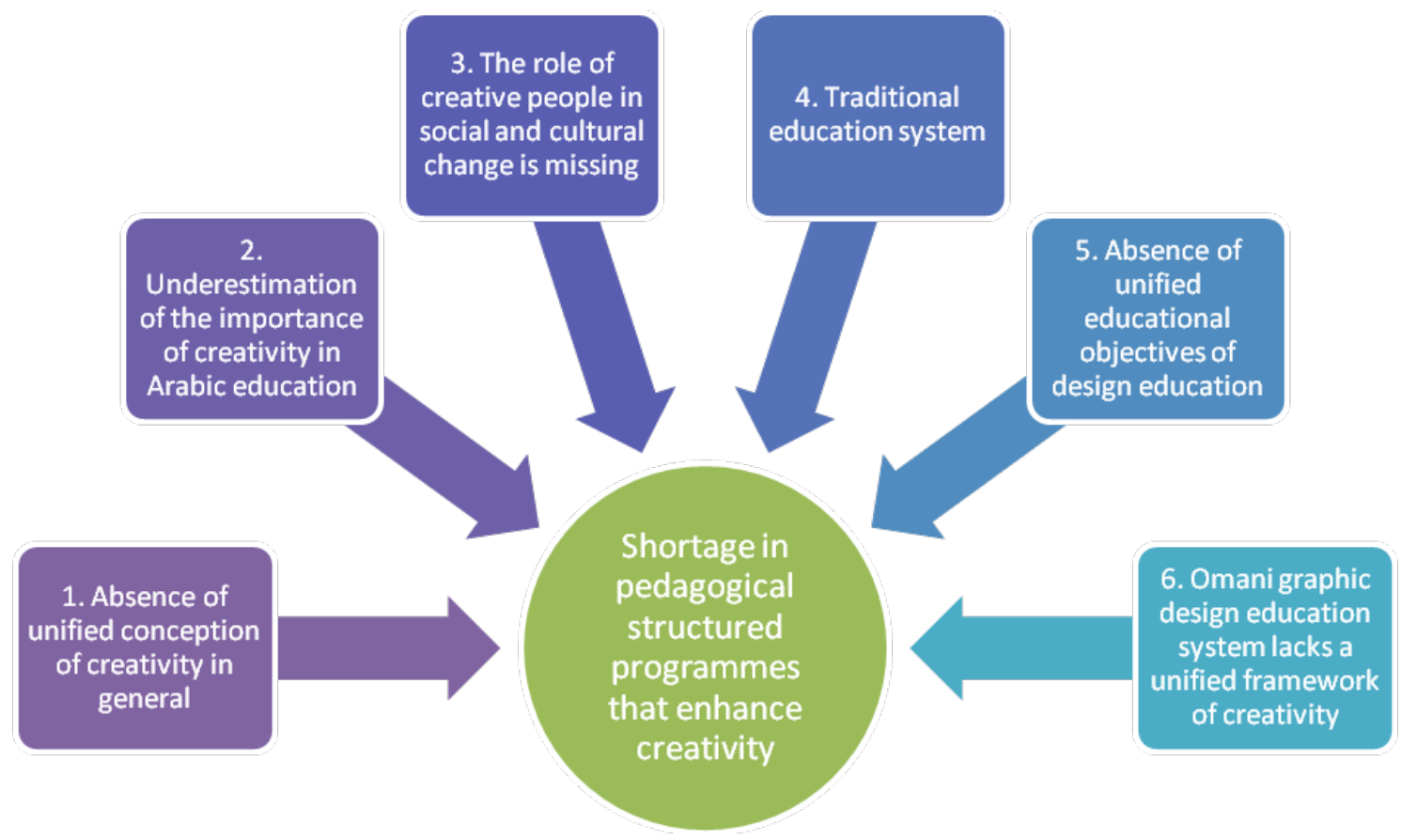

Figure 1. The causes of the research problem

Another argument that underpins this research is that "the individual creative description is part of the general process which creates conventions and institutions, through which the meanings that are valued by the community are shared and made active". Therefore, it can be argued that if educators are interested in establishing a central role for creativity in universities and higher education institutions, they need to ensure that there are suitable opportunities, a supportive environment, and enthusiastic motivation for their students. This is in addition to activating innovative and imaginative experiences whilst teaching graphic design. But, more importantly, it is argued that to ensure the flourishing of graphic design education in developing countries, a deep understanding of the importance of creativity is required in the first place.

\section{If educators are interested in establishing a central role for creativity in universities}

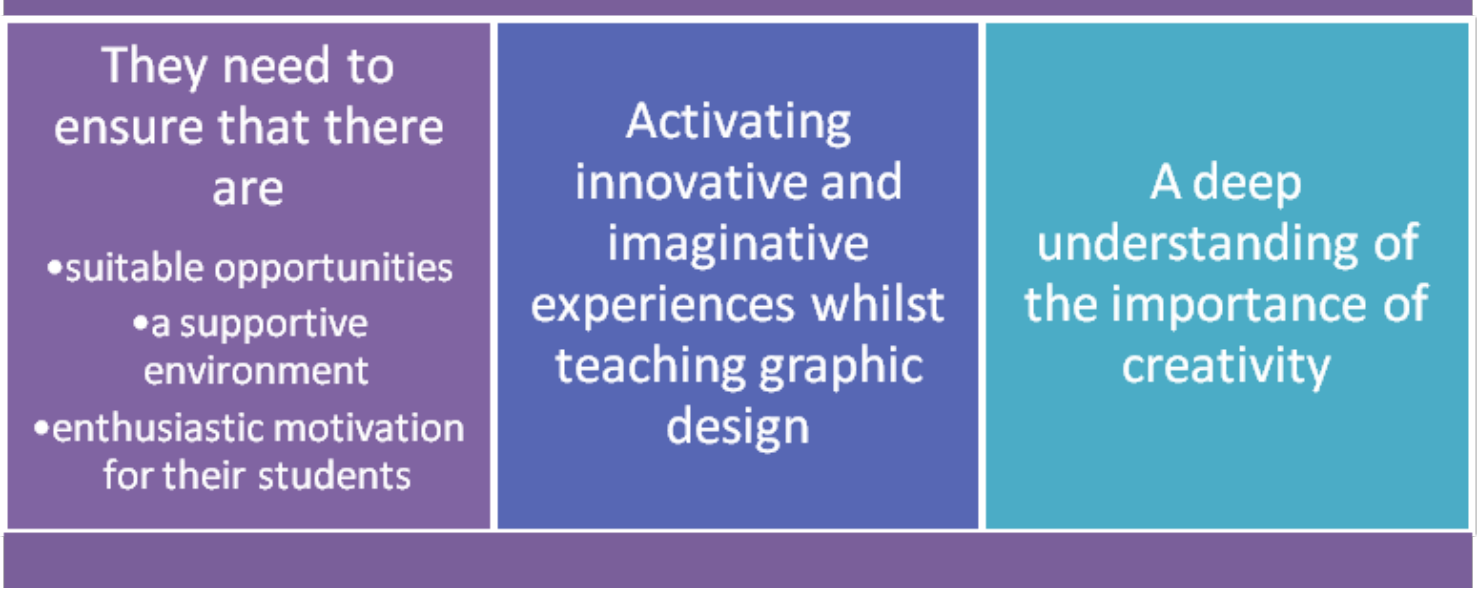

Figure 2. Educators' roles in establishing a central role for creativity in universities 


\section{Traditional Omani Graphic Design Education}

Graphic design is a broad area of study. It is believed that graphic designing is a quite 'creative' practice and requires thorough problem solving skills. In the field of graphic design, most literature entails the processes used in the field. Besant, Whyte and Neely [3] believed that design is a purposive application of creativity and leads to a vast array of innovations.

A number of complex processes take place during the problem solving process involving designs. The practice of Graphic design is not an exception and the diverse problem-solving contexts in the field of graphic design are addressed by the use of a particular design language [4].

In the traditional design educational environment, graphic design teachers use very basic tools such as pencils, sketches, paper, brushes, and rulers for teaching graphic skills. This type of education is explained in Heller [5, p42] who clarifies how graphic students usually study typography via traditional methods: "many of them (instructors) teach traditional methods, such as setting type by hand and printing by letterpress". However, such traditional methods can develop certain qualities with students, for example; sketching techniques with early graphic design students. Sevak $[6, p 3]$ argues that it can "train mind and hand coordination skill". Interaction with the medium, which is part of the creative process, redefines established solutions and promotes the development of imagination.

The traditional environment means here the conventional system of teaching graphic design, such as manual cut and paste. In other words, it is all about being 'hands on' in producing a piece of design. Such a system usually focuses on the study of materials and mediums of basic design such as understanding colour, form, shape, texture, light, and composition. It trains students to draw and paint, and teaches them colour theories, colour circles, 2D and 3D shapes and forms, space, background and texture, poster illustration and the execution of the complete design through manually using poster colour or Gouache colour. Even though the basic tools used in this type of education can develop certain skills and intellectual abilities amongst graphic design students, its role in fostering students' creativity requires further investigation.

\section{Discussion}

As a graphic design lecturer, it is believed that traditional methods are very valuable in terms of training students to understand, comprehend, and follow the creative design process. This is because traditional graphic design teachers prioritize technical skill over design thinking [6]. Teaching graphic design within a traditional environment, educators have been able to challenge students to be more questioning about their use of new technologies. Lecturers within Omani educational culture usually prefer students who "are courteous and considerate of others, punctual, energetic and industrious, popular with their peers, well rounded, receptive to other people's ideas, and obedient" [7].

To sum up, successful systems of teaching graphic design may require the use of advanced technologies alongside certain traditional educational methods. Kelly [8, p153] asserts that the "computer provides the student with endless options of size, arrangement, choices and colours. Each option is an opportunity to make a decision". It is argued here that the only thing worse than a solely digital design education, is a solely analogue one. Therefore, traditional design education should take its place along with computerised learning, especially in the early years of any graphic design study plan. This would help students to explore their skills, particularly those who do not have much background in art and design. Mastering some graphic software does not make one a designer [6]. The software is used in place of tools and makes the process easier, but it does not train the mind and hand. Also, "it is necessary to teach the design basics first, with the customary tools and media, leaving computers for more advanced work" [9, p74]

\section{The Computerised Omani Design Education}

Most Omani governmental and private institutions apply both analogue and computerised environments in teaching graphic design to undergraduate students. The computerised design education means here, the availability of advanced computers and devices that would help graphic students to produce a piece of design more quickly, but not necessarily better, more appropriately or more creatively. A computerised environment provides a high level of digital facilities by offering a wider variety of solutions for most design problems. Therefore, it is argued that a computerised environment can promote creative thinking and stimulate students' behaviour. Lubart [10, p365] argues, "Computers may facilitate the management of creative work, communication between individuals collaborating on creative projects, the use of creativity enhancement techniques, and enhance the creative act through integrated human-computer cooperation during idea production".

It is argued here that the graphic design student in such a computerised environment becomes more active, enthusiastic, and creative. Kelly [8, p4] argues, "Computers became the significant factor in graphic design that they are today. The assimilation is so complete that it is now impractical to conceive of teaching graphic design without computers". As a result, analogue and digital technologies affect the definition of creativity, and in terms of digital technologies can foster the process of problem solving, by providing advanced devices that offer multiple solutions for a single problem. Yet, the problem solving process remains the same in both the analogue and digital environments. The purpose of comparison between these two environments is to investigate the integrated roles of the two.

\section{The Importance of Traditional and Computerised Systems}

It is important to use both analogue and digital education systems in enhancing students' creative problem solving. This is because teaching graphic design in a computerised 
environment plays a very important role in producing quicker solutions to design problems. Also, computers can enhance creative thinking skills and develop the artistic abilities of graphic design students [6, 8]. However, the use of computers only affects the speed at which a solution is produced; it does not ensure the correctness.

It is rational to argue that designers can work more efficiently to increase production with computers, but would that necessarily mean that creativity is enhanced accordingly? Kelly [8, p152] argues, "The designer's current fascination with the computer is easy to understand. With the computer it is possible to do easily and quickly those things that it was difficult and time-consuming to do in the past". Cheow [11] argues, "Educators need to define what roles graphic designers should be aware of in their human-computer interactivity and what skills need to be nurtured". Therefore, it is strongly recommended to use both computer tools and traditional tools and media equally. However, further investigation is required here.

There are disadvantages of using computers in graphic design, as stated by Cheow [11] "Although the computer is known for expediency, precision and rendering abilities, it falls short in imitating the quirky and raw qualities of hand crafted letterforms". Physical intersections can also be used interchangeably along with digital design. It is important that students focus on learning about design, rather than how to design.

Alkholy [9, p74] argues also that,

"Computer is a great tool that has made both academic research and creative art and design easier, faster, further accurate, and more interesting, but there is enormous misunderstanding about its role in graphic design. Its tools will not work properly without a good experienced and a practiced hand to control. Most students assume that computer is the goal, the more you know the better designer you are."

It is worth noting that some sort of digital working is now a cultural and economic default (e.g. the means of ideation (CAD) are digitally but not physically proximate to the means of production (CAM)). Any other approach is more difficult to enact, is therefore going to be less common and so needs to be addressed in a an educational context less frequently. So underplaying the digital is just not going to happen in graphic design education. At the same time, nobody argues that computers can make creative designers. This research is not testing this notion anyway; it is covered in this section only to see how local (i.e. Omani lecturers) value using both computerised and analogue education environments.

\section{Conclusions}

To sum up, teaching graphic design in a computerised environment is central, simply because, "graphic design education is now being shaped by technology" [8, p40].
However, through a deep investigation of the existing literature, it has been discovered that there are fewer studies discussing the importance of both the analogue and computerised environments in enhancing the creativity of graphic students. This can be regarded as a gap in the literature; therefore, the research on hand intends to fill this gap. Further investigation is required through collecting empirical data by means of a questionnaire and interviews. Interview methods of this study have investigated the situation of creativity in the Omani graphic design educational context, and confirmed the importance of both the analogue and computerised environments in enhancing creativity of graphic students.

\section{REFERENCES}

[1] Almusa, A. 'Saudi Creativity Academy 2020 Project', in Confratute Conference University of Connecticut, Connecticut: Division of Exceptionalities and Bilingual/ESL Education University of Northern Colorado. 2004.

[2] Barnard, M. Graphic Design as Communication, London: Routledge; 2005.

[3] Bessant, John, J. Whyte, and A. Neely. "Management of creativity and design within the firm, DTI Think Piece." Advanced Institute for Management (AIM) and Imperial College. 2005.

[4] Tan, Stella, and Gavin Melles. "An activity theory focused case study of graphic designers' tool-mediated activities during the conceptual design phase." Design Studies. 2010: 31(5): 461-478.

[5] Heller, Steven. The Education of a Typographer. New York: Skyhorse Publishing Inc; 2004.

[6] Sevak, Pravin. Moving Forward: Graphic Design Teaching And Technology, Online Proceedings of MX Design Conference 'Design Perspectives. University of Iberoamericana, Mexico City; 2003. Available at http://www.dis.uia.mx/conference/2005/HTMs-PDFs/pravin _sevak.htm.

[7] Cropley, Arthur. More Ways Than One: Fostering Creativity. Norwood, New Joursy: Ablex Publishing Corporation; 1992.

[8] Kelly, Rob. Constraint Vs . Restraint, pp. 147-157, in: Graphic Design and the Computer. 2002. Available at http://www.rit.edu/library/archives/rkelly/resources/pdf/03_p ed/ped_cmp.pdf.

[9] Alkholy, Inas. "Teaching Graphic Design in Jordan: Theory and Practice, in: Proceedings Design train Congress Trailer I, May 2007." Amsterdam, The Netherland. 2007: 70-78.

[10] Lubart, Todd. "Creativity and Cross-cultural Variation." International Journal of Psychology. 1990: 39-59.

[11] Cheow, Yeoh. "Do Computers Undermine The Creative Process?", 2006. Accessed 22 February 2010. Available at http://www-des.tp.edu.sg/des_yeoh_kok_cheow.pdf. 